\title{
Culture-Specific Assets to Consider When Counseling Latina/o Children and Adolescents
}

\author{
José A. Villalba Jr.
}

Strength-based cultural considerations for counseling Latina/o children and adolescents are not well articulated in the literature. Furthermore, research and demographic data indicate concerns for Latinas/os, such as acculturative stress and discrimination. This article describes treatment applications focused on Latina/o youth's cultural strengths, including family bonds, bilingual abilities, and bicultural skills.

Métodos de conserjería basados en rasgos positivos de niños y adolescentes Latinos no se han articulado en la literatura. Además, las investigaciones y los datos demográficos presentan problemas con respeto a presión de acultivación, discriminación, y habilidad limitada en Ingles. Este artículo describe tratamiento centrado en los rasgos culturales positivos de la juventud Latina incluyendo enlaces de la familia, las capacidades bilingües, $y$ las habilidades biculturales.

atinas/os now are considered the largest minority group in the United States. According to the most recent U.S. Census data, there are over 41 $\mathbb{A}_{\text {million Latinas/os living in the United States, accounting for } 14.1 \% \text { of }}$ the overall population (U.S. Census, 2005a). Although the U.S. Census categorizes Latinas/os living in the United States as "Hispanic, of any race," for the purposes of collecting and tabulating data, the U.S. Latino population actually comprises very different peoples. Latina/o immigrants continue to come to the United States from over 19 Caribbean, Central American, and South American countries. Many of these immigrants have arrived recently, with over $50 \%$ of foreign-born Latinas/os having entered the United States after 1990 (Pew Hispanic Center, 2005). However, almost $60 \%$ of Latinas/os living in the United States were born in the United States (U.S. Census, 2003). Despite the size and continual growth in the U.S. Latino population, many Latinas/os living in the United States experience stressors related to racism and discrimination, acculturative distress, and high poverty rates (Ordoñez-Jasis \& Jasis, 2004; Schwarzbaum, 2004).

Latinas/os are also the fastest growing and youngest minority group in the United States (i.e., 34\% of Latinas/os are under the age of 18 years; U.S. Census, 2005a). Because of the relative youth of the U.S. Latino population, Latina/o children and adolescents are the largest minority group in U.S. schools, accounting for $18 \%$ of all elementary, middle, and high school students enrolled in U.S. public and private schools (U.S. Census, 2005b). At the same time, Latino/a children

José A. Villalba, Jr, Department of Counseling and Educational Development, University of North Carolina at Greensboro. Correspondence concerning this article should be addressed to José A. Villalba Jr., Department of Counseling and Educational Development, PO Box 26170, University of North Carolina at Greensboro, Greensboro, NC 27402-6170 (e-mail: javillal@uncg.edu). 
and adolescents enrolled in U.S. schools encounter problems with becoming familiar with the school environment, have lower test scores compared with those of their peers, and have high dropout rates (Clemente \& Collison, 2000; Livingston \& Wirt, 2004; U.S. Census, 2005b). The pressures related to negative experiences may prompt some Latina/o children, adolescents, parents, and guardians to seek the assistance of a mental health specialist. Therefore, the purpose of this article is to present strength-based cultural considerations to assist mental health providers serving children and adolescent Latina/o clients. Strength-based cultural considerations frame cultural traits, traditions, customs, and languages as assets instead of deficits, such as reframing traditional, culturally based family unity and social behaviors as personal assets for confronting stressors (Collatos, Morrell, Nuno, \& Lara, 2004).

\section{demographic characteristics and experiences of latinas/os in the united states}

Because of the heterogeneity of the Latina/o demographic group as a whole, counselors, supervisors, counselors-in-training, and counselor educators are discouraged from categorizing all Latinas/os as having the same experiences and sharing the same characteristics. However, there are a few general statements, grounded in the literature (e.g., Casas, Furlong, \& Ruiz de Esparza, 2003; Santiago-Rivera, Arredondo, \& Gallardo-Cooper, 2002) and validated through empirical research (e.g., Pew Hispanic Center, 2005; Toro-Morn, 1998), that can be made about many Latinas/os living in the United States. A common generalization about Latinas/os living in the United States is that they consider themselves to be bilingual or use Spanish as their dominant language (Pew Hispanic Center, 2005). Specifically, 47\% of Latinas/os surveyed by the Pew Hispanic Center (2005) reported Spanish as their dominant language, and another $28 \%$ indicated that they were bilingual, compared with $25 \%$ who reported English as their dominant language. Another general characteristic among Latinas/os is the importance of family ties and the propensity to live with or close to extended family members (Santiago-Rivera et al., 2002). Because of the need to deal with the physical and legal issues involved with the immigration experience, most Latinas/os (especially recently arrived immigrants) have developed the common and helpful trait of resiliency (García Coll \& Magnuson, 1997). Finally, some authors (e.g., Feliciano, 2001; Gopaul-McNicol \& Thomas-Presswood, 1998) highlight the ability of many Latinas/os to effectively and efficiently balance their native culture with mainstream U.S. culture.

There also are several social, emotional, and physical concerns for Latinas/os living in the United States (Casas et al., 2003). For example, the immigration status of Latina/o children and their families has a direct impact on their 
perceptions and use of social and educational services and also on their willingness to seek out medical and social services (de Leon Siantz, 1997). Often, Latinas/os who are in the United States illegally will not take full advantage of the assistance available to them (e.g., free education for their children, social services, health care) for fear of being deported, arrested, or losing a job (de Leon Siantz, 1997). The immigration ordeal (leaving family behind, separation from parents during the migration process, violence and trauma resulting from entering the United States through illegal channels) may also be a reason for distress and consternation among Latina/o immigrants, particularly children (García Coll \& Magnuson, 1997). Furthermore, the living and working conditions many Latinas/os encounter when they arrive in the United States further complicate their personal, social, and psychological wellbeing (Toro-Morn, 1998). Specifically, Toro-Morn reported that Puerto Rican immigrants experienced mental distress when relocating from Puerto Rico to U.S. cities due to the overcrowded living conditions and poor housing they encountered after their arrival. In addition, the majority of jobs available to Latina/o workers in the United States can be classified as low-paying, requiring long hours, undesirable, arduous, and unsafe (Casas \& Arbona, 1992; Judy \& D’Amico, 1999). Finally, Latinas/os have a propensity for certain medical ailments (e.g., diabetes, heart disease, and hypertension), which leads to health disparities when compared with their White peers, owing to the lack of both access to care and the multicultural competencies of providers (Zsembik \& Fennell, 2005).

Another issue concerning Latinas/os is discrimination, including reports of racial profiling, verbal abuse, displaced anger regarding immigration due to the experience of the terrorist attacks of $9 / 11$, on-the-job discrimination, hate crimes, and stereotypical assumptions that "they can't speak the language" and do not wish to assimilate (Fox \& Stallworth, 2005; Hovey \& King, 1996; Pew Hispanic Center, 2004; Smart \& Smart, 1995; Williams \& Berry, 1991). Latina/o parents reported that their children are quickly labeled as possessing a learning disability or having a behavioral problem, have teachers who harbor lower expectations of their children, and have teachers who do not know how to deal with children from different cultures (Pew Hispanic Center, 2004). The U.S. Census (2003) also reported that Latinas/os children and adolescents are more likely to live in poverty and are less likely to have completed a high school education. The regrettable results of these social, physical, and economic experiences for Latinas/os contribute to systemic challenges for Latina/o children and adolescents, such as personal-social and academic concerns associated with their educational attainment, limited post-high school occupational opportunities, poverty, high dropout rates, cultural identity issues, gang activity and violence, and an inability to adjust to new academic and social environments (Brigman \& Campbell, 2003; Gibson \& Bejínez, 2002; Pew Hispanic Center, 2004; Santiago-Rivera et al., 2002; Smart \& Smart, 1995; Villalba, 2003). 


\section{reframing challenges for latina/o children and adolescents by emphasizing latino cultural assets}

As also reviewed in the previous pages, most of the literature on the living and educational conditions of Latina/o children and adolescents has articulated the difficult environments and social limits experienced by many Latinas/os living in the United States, including but not limited to limited-English proficiency, academic deficiencies, inability to understand and participate in U.S. social institutions (schools, politics, the justice system), limited educational attainment, low wages and earning rates, as well as the health disparities as compared with White peers (Clemente \& Collison, 2000; Judy \& D'Amico, 1999; Santiago-Rivera et al., 2002; Zsembik \& Fennell, 2005). Bernal, Saenz, and Knight (1995) categorized this view of Latinas/os as itself being a "culturally deficient" (p. 77) perspective in that it portrays all Latinas/os as socially, economically, emotionally, physically, and cognitively unfulfilled. Such a perspective cannot be accurately applied to the entire U.S. Latino population and is not altogether useful for working with this population. Although it is important for counselors and counselors-in-training to be aware of the statistical and historical data relevant to Latina/o clients, it is not necessarily helpful for these clients (and their counselors) to focus strictly on obstacles and negative outcomes.

The first step in moving away from a culturally deficient basis for counseling is to reframe challenges by emphasizing a cultural assets framework, whereby a counselor engages in the continual development of multicultural competence (increasing awareness, knowledge, and skills related to counseling diverse populations; Arredondo, 1999) while presenting an attitude and professional demeanor open to the strengths of Latina/o children and families. It is also paramount for the counselor to consider the strengths of Latina/o clients rather than their deficits, which enhances the level of understanding between clients and counselors (Santiago-Rivera et al., 2002). Focus on the following three culture-specific assets Latina/o clients—-being bilingual, being bicultural, and having the strength they derive from family bonds-is intended to assist mental health services providers with developing strength-based perspectives and interventions for Latina/o youth. In addition, counselor educators are encouraged to infuse this perspective of the culture-specific assets of Latina/o clients into their courses and throughout the counseling curriculum.

\section{ENCOURAGING LATINA/O YOUTH TO USE BILINGUAL LANGUAGE PROFICIENCIES AS AN ASSET}

As the United States becomes more diverse and the economic prosperity of the country becomes more interconnected with global demands, being fluent in two or more languages increases a person's chances of being hired for a particular job and attaining long-term, work-related success (Judy \& D'Amico, 1999). Whereas many individuals must rely on cursory knowledge of a language 
other than English to bolster their opportunities in an increasingly competitive workforce, many Latina/o students have the advantage of being fluent in two languages by the time they graduate from high school (Crawford, 1999). Yet how many Latina/o children and adolescents are made aware of the advantages of being bilingual and fluent in Spanish and English, such as serving as translators for parents, reading Spanish and English newspapers, or listening to a World Cup soccer match in Spanish when an English broadcast is unavailable?

Because of the pressure to acculturate into U.S. schools and societies, Latina/o children and parents often believe it is in their best interest to neglect their Spanish fluency in favor of learning English as quickly as possible (Crawford, 1999). This misconception is reinforced by teachers, educators, and community leaders who also adhere to the notion that fully immersing non-native-English speakers in English classes is the best way for them to learn English and help them make an easy transition into U.S. culture (Cummins, 1994). However, if being bilingual in English and Spanish is a worthy and often necessary trait for the current and future workforce (Bridges, 1994), then Latina/o children and adolescents should be made aware of the unique advantages their bilingual abilities provide them.

Counselors and other mental health providers are in an advantageous position to empower Latina/o youth by encouraging them not to forget or forego their Spanish fluency (Clemente \& Collison, 2000; Villalba, 2003). Collatos et al. (2004) particularly emphasized the need for adults working with Latino/o adolescents to focus on the strengths these children derive from their culture and language, as opposed to focusing on a deficit model of what these children do not possess. Furthermore, Franklin and Soto (2002) indicated that service providers working with Latina/o youth should not be focusing on the limited-English language proficiency but instead should empower students (and other counselors working with this population) by reminding them of their native language skill. Therefore, if Latina/o children express a desire to neglect or ignore their Spanish-language abilities, counselors can promote the consideration of the benefits related to being fluent in two languages. As a benefit of their newfound awareness, Latina/o youth may experience increased self-esteem, self-efficacy, and post-high school expectations (Crawford, 1999; Cummins, 1994; Gopaul-McNicol \& Thomas-Presswood, 1998).

\section{INTERVENTIONS TO REINFORCE BILINGUALISM}

It may be possible for mental health specialists to use individual counseling and group counseling with Latina/o youth to assist them to reframe their bilingual skills as an asset. For example, cognitive-behavioral therapy (CBT) with individual Latina/o youth and adults has been proven to be effective in dealing with anxiety and stress (Pina, Silverman, Fuentes, Kurtines, \& Weems, 2003; Ponterotto, 1987). With Latina/o youth, CBT strategies can be implemented whereby the clinician encourages the young Latina/o client to discuss the positive and negative attributes of learning English and Spanish as well as being bilingual. The clinician may then direct the client to focus on the 
positive factors (e.g., through journaling, audio recording on benefits of being bilingual in English and Spanish) while developing strategies for dealing with the negative factors associated with being bilingual (e.g., making a list to be discussed in session with a clinician). Also, the use of a psychoeducational group designed to empower Latina/o students by having them focus on their overlooked language strengths may also instill feelings of universality and mutual support (Torres-Rivera, 2004; Villalba, 2003).

Counselors can also design and implement a small group for Latina/o youth who are learning English as a second language. In this case, the focus of the psychoeducational group may be to assist members to continue to practice their English proficiency in a safe environment, in addition to coping with acculturative and academic stress and difficulties associated with learning a new language. Counselors leading these types of groups also increase their knowledge of Latino culture and their Latina/o clients. These mutually beneficial client-counselor relationships can lead these children and adolescents to have a more positive outlook and self-concept (Cummins, 1994).

\section{ENCOURAGING LATINA/O YOUTH TO USE BICULTURAL SKILLS AS AN ASSET}

Being bicultural, or having the ability to understand and operate in two distinct cultures, often manifests itself in children (including immigrant youth) as a need to remain loyal to their cultural heritage while accepting the reality of having to assimilate into mainstream society (Feliciano, 2001). However, there is an inherent difficulty in simultaneously understanding and navigating two distinct cultures in addition to being accepted in both cultures (Cummins, 1994; Phinney, Cantu, \& Kurtz, 1997). An area of particular discomfort may be linked to having to focus on the mores and customs of an unfamiliar and new culture while trying to remain loyal and connected to a native culture (Santiago-Rivera et al., 2002). However, the complex notion of living in and balancing two or more cultures is worthy of praise, admiration, and acknowledgment and could be demonstrative of resiliency that could be useful in reducing the effects acculturative stress (Gordon, 1996). Simultaneously functioning in two distinct environments or cultures can also help build skills that Latina/o youngsters can use in the future for adjusting to and thriving in a variety of systems (e.g., jobs and careers, personal relationships, new communities, college or university; Judy \& D'Amico, 1999).

Feliciano (2001) studied the academic success of immigrant Asian and Latina/o students as measured by their likelihood of dropping out of high school. She found that bicultural students, those who had not abandoned their native culture and language while accepting their need to succeed in mainstream society, were more successful in school and were more positive about their future. She indicated that it was these youngsters' skills in finding support in both cultures that led them to be better adjusted than those who were polarized toward the native culture or mainstream society. Other researchers have reported that bicultural youth demonstrated fewer conduct 
disorders (Szapocznik, Kurtines, \& Fernandez, 1980) and symptoms of depression (Kaplan \& Marks, 1990) than did their peers who fully assimilated into mainstream society, and they displayed more effective methods for functioning in various sociocultural situations than did their fully assimilated peers (Coatsworth, Maldonado-Molina, Pantin, \& Szapocznik, 2005).

It must be stressed, however, that at no point should a mental health professional fail to validate the cultural conflicts Latina/o children and adolescents may encounter at home as a result of parents who do wish their children to adhere to traditional values, at school where these children may feel pressure from teachers to acculturate to U.S. customs, or in social settings (e.g., after-school programs, social functions, organized sports) in which peers may harass them for being different or "not talking right." Therefore, it is recommended that counselors set individual and group counseling goals focused on increasing the awareness and reframing of Latina/o youth's bicultural skills and using bicultural skills in various academic and social settings to cope with cultural conflicts. In addition, counselors, counselors-in-training, supervisors, and counselor educators are encouraged to highlight the personal-social and cognitive skills (e.g., speaking two languages, managing different sets of nonverbal cues, understanding how cultures can coexist even if they differ in certain values and beliefs) necessary for someone to balance the factors and variables of two cultures (Feliciano, 2001; Gordon, 1996). Counselors may also elect to focus on the strength and resilience of their young clients in the face of having to juggle a traditional Latino culture at home and a new and developing American culture in their schools (Feliciano, 2001; Gordon, 1996). For example, children can help parents understand that they are learning how to balance both Latino and American cultures, which is more desirable in today's economy, or they may be encouraged to share with teachers and peers how their bicultural perspectives frame their views of history or even fashion trends.

\section{ENCOURAGING LATINA/O YOUTH TO USE IMMEDIATE AND EXTENDED FAMILY UNITY AS AN ASSET}

Formally, familismo is the preference most Latinas/os have to preserve close family ties while emphasizing cooperation among immediate and extended family members (Santiago-Rivera et al., 2002). The commonly held view of the average Latino family is that of a large immediate family, with extended family members (i.e., aunts, uncles, cousins, grandparents, godparents, and great-grandparents) taking part in all aspects of decision making for the immediate family (Santiago-Rivera et al., 2002). Research does indicate that over a quarter of Latino households are made up of five or more people, compared with roughly $11 \%$ of non-Latino, White households having five or more members (U.S. Census, 2003). Furthermore, many writers have reported that the extended Latino family unit is considered to be a source of support, information, advice, and comfort in times of joy and tribulation (Esquivel \& Keitel, 1990; Hovey \& King, 1996; Santiago-Rivera et al., 2002; Smart \& Smart, 1995; Torres-Rivera, 2004). Therefore, counselors should challenge Latina/o 
youth to consider the immediate and extended family ties of support and guidance as facilitative factors in dealing with social challenges and barriers.

For Latina/o youngsters who are first generation or recently arrived in the United States, the interconnectedness of the immediate and extended family can be viewed either as helpful or, in the case of those acculturating into mainstream society, cumbersome (Esquivel \& Keitel, 1990). For some Latina/o children, the family is the unit they look to for answers to difficult questions, help with school tasks, or support when learning a new language. In contrast, other Latina/o children and adolescents struggle with the intrusiveness of parents and family members as they try to become more familiar with mainstream customs, make non-Latina/o friends, and try to establish a niche for themselves in their school and community settings. However, most Latina/o children and adolescents (regardless of acculturation), who are unhappy with their family's adherence to cultural values related to familismo, still acknowledge the benefits of familial support in times of social and scholastic difficulty (Hovey \& King, 1996). In cases in which Latina/o youth are struggling with personal-social stressors or acculturative stress, mental health specialists can assist them to consider the positive effects of familismo on their experiences.

When Latina/o youth are considering the influence of the family unit when dealing with unpleasant experiences, it is also important for them to focus on the concept of resiliency. Resiliency refers to the ability certain individuals have to persevere educationally, economically, and psychologically despite numerous hardships and obstacles (Cabrera \& Padilla, 2004). Some authors (e.g., Collatos et al., 2004; de Leon Siantz, 1997; Gordon, 1996) stressed that the historical and personal resiliency of this group has contributed to the U.S. Latino population boom, advances in politics and positions of power, and slow but steady improvements in educational achievement gaps. These same authors indicated that the resiliency displayed by large numbers of Latina/o children and adults is directly related to the importance relegated to the family unit in the Latina/o culture, because family and community support play a crucial role in maintaining resilience despite hardships. Therefore, for Latina/o children who are in counseling, family and cultural resiliency may become points of interest when considering counseling goals and objectives.

\section{INTERVENTIONS TO REINFORCE FAMILISMO AND RESILIENCY}

Just as there are strategies for emphasizing the culture-specific assets of being bilingual and bicultural, there are different ways in which to consider Latino family involvement and issues of resiliency when counseling Latina/o youth. For example, person-centered counseling with adolescent Latina/o clients (Coatsworth et al., 2005) can be used whereby the counselor facilitates the client's awareness of her or his family's closeness, resiliency, and unity. In this case, the counselor may use the principles of empathy, genuineness, and unconditional positive regard in having the Latina/o youngster describe the makeup of his or her family, both immediate and extended and those living in this country 
and in the country of origin. Next the client and counselor can work together to determine if there are particular family members who may be of specific assistance to the child and his or her related problem (i.e., if the Latina/o client is having trouble adjusting to school, perhaps there is an older cousin who may have experienced similar issues). Related approaches could be undertaken in designing psychoeducational groups for newcomer Latina/o children in school settings or community settings. Regarding resiliency and the family, a psychoeducational group session may involve having members describe their family's experiences in this country while also highlighting occurrences of perseverance by specific family members. Finally, as suggested by Torres-Rivera (2004), parents or guardians and extended family members can be invited to counseling sessions or parent information sessions in an effort by the counselor to show the client that her or his family is valued in clinical settings.

\section{limitations of reframing challenges for latina/o children and adolescents}

There are limitations to automatically reframing cultural traits, customs, and traditions as positive attributes. In a previous section, we have already cautioned mental health providers against invalidating the impact of bicultural stress, becoming proficient in two languages, and the incongruence between home culture (i.e., Latino culture) and school culture (i.e., American culture) on Latino youth. So, when a counselor says "keep your own culture" as well as "adopt a second culture," does it lead to mixed messages for a psychologically impaired mental health client (G. Roysircar, personal communication, June 22, 2006), which may lead to an unclear understanding of the counseling relationship and unpleasant feelings toward mental health care on the part of the Latina/o youngster? Another limitation relates to the participation of Latina/o youth in mental health services. Because Latina/o children and adults are less likely to use mental health services and have higher rates of counseling dropout when compared with non-Latina/o peers (Schwarzbaum, 2004; U.S. Department of Health and Human Services, 2001), it becomes paramount for counselors to carefully address and consider all of their Latina/o clients' motives for seeking mental health assistance. Therefore, counselors should determine if bicultural, bilingual, and familial stressors are too great (with the potential to lead to more serious issues such as depression, suicide, substance abuse, violence, running away) before reframing contextual multiplicity as being universally considered to be positive assets by Latina/o children and adolescents.

\section{conclusion}

Latina/o families and children may experience a variety of challenges and pressures, including systemic obstacles, personal-social struggles, and acculturative stress. Mental health professionals, regardless of their clinical settings, 
have the opportunity to assist Latina/o children and adolescents with their development and coping skills as they seek to manage and counter the effects of conflicts and personal, social, and economic difficulties. The culture-specific assets of bilingualism, biculturalism, and familismo should be considered by Latina/o children and adolescents as effective methods for reframing and coping with unpleasant experiences. Fortunately, many Latina/o children and adolescents possess these culture-specific assets. Becoming consciously aware of their culturespecific assets, learning how to use them when necessary, and understanding the relationship between these assets and the U.S. Latino culture can be beneficial for Latina/o children and adolescents who are working with a mental health specialist. Counselors and counselors-in-training must strive to find a place for these culture-specific assets in their work with Latina/o children and adolescents. In addition, counselor educators must incorporate the concept of culture-specific assets in their instruction as a way to challenge culturally deficient theoretical perspectives, specifically as they relate to Latina/o children and adolescents.

\section{references}

Arredondo, P. (1999). Multicultural counseling competencies as tools to address oppression and racism. Journal of Counseling Eै Development, 77, 102-108.

Bernal, M. E., Saenz, D. S., \& Knight, G. P. (1995). Ethnic identity and adaptation of Mexican American youths in school settings. In A. Padilla (Ed.), Hispanic psychology: Critical issues in theory and research (pp. 71-88). Thousand Oaks, CA: Sage.

Bridges, W. (1994). Job shift: How to prosper in a workplace without jobs. Reading, MA: Perseus Books.

Brigman, G., \& Campbell, C. (2003). Helping students improve academic achievement and school success behavior. Professional School Counseling, 7, 91-98.

Cabrera N. 1., \& Padilla, A. M. (2004). Entering and succeeding in the "culture of college": The story of two Mexican heritage students. Hispanic Joumal of Behavioral Sciences, 26, 152-170.

Casas, J. M., \& Arbona, C. (1992). Hispanic career related issues and research: A diverse perspective. In D. Brown \& C. Minor (Eds.). Report of second Gallup survey: Forus on minorities. Alexandria, VA: National Career Development Association.

Casas, J. M., Furlong, M. J., \& Ruiz de Esparza, C. (2003). Increasing Hispanic parent participation in schools: The role of the counselor. In P. B. Pedersen \& J. C. Carey (Eds.), Multicultural counseling in the schools: A practical handbook (pp. 105-130). Boston: Allyn \& Bacon.

Clemente, R., \& Collison, B. B. (2000). The relationship among counselors, ESL teachers, and students. Professional School Counseling, 3, 339-349.

Coatsworth, J. D., Maldonado-Molina, M., Pantin, H., \& Szapocznik, J. (2005). A person-centered and ecological investigation of acculturation strategies in Hispanic immigrant youth. Joumal of Community Psychology, 33, 157-174.

Collatos, A., Morrell, E., Nuno, A., \& L ara, R. (2004). Critical sociology in K-16 early intervention: Remaking Latino pathways to higher education. Journal of Hispanic Higher Education, 3, 164-179.

Crawford, J. (1999). Bilingual education: History, politics, theory, and practice (4th ed.). Los Angeles: Bilingual Educational Services.

Cummins, J. (1994). Knowledge, power, and identity in teaching ESL. In F. Genesee (Ed.), Educating second language children. New York: Press Syndicate of the University of Cambridge.

de Leon Siantz, M. L. (1997). Factors that impact development outcomes of immigrant children. In A. Booth, A. Crouter, \& N. Landale (Eds.), Immigration and the family: Research and policy on U.S. immigrants (pp. 149-161). Mahwah, NJ: Erlbaum.

Esquivel, G. B., \& Keitel, M. A. (1990), Counseling immigrant children in schools. Elementary School Guidance and Counseling, 24, 213-218.

Feliciano, C. (2001). The benefits of biculturalism: Exposure to immigrant culture and dropping out of school among Asian and Latino youth. Social Science Quarterly, 82, 865-879.

Fox, S., \& Stallworth, L. E. (2005). Racial/ethnic bullying: Exploring links between bullying and racism in the U.S. workplace. Joumal of Vocational Behavior, 66, 438-456. 
Franklin, C. G., \& Soto, I. (2002). Keeping Hispanic youths in school. Children and Schools, 24, $139-143$.

Garcia Coll, C., \& Magnuson, K. (1997). The psychological experience of immigration: A developmental perspective. In A. Booth, A. Crouter, \& N. Landale (Eds.), Immigration and the family: Reseanh and policy on U.S. immigrants (pp. 91-132). Mahwah, NJ: Erlbaum.

Gibson, M. A., \& Bejinez, L. F. (2002). Dropout prevention: How migrant education supports Mexican youth. Joumal of Latinos and Education, 1, 155-175.

Gopaul-McNicol, S., \& Thomas-Presswood, T. (1998). Working with linguistically and culturally different children: Innovative clinical and educational approaches. Boston: Allyn \& Bacon.

Gordon, K. A. (1996). Resilient Hispanic youth'self-concept and motivational patterns. Hispanic Joumal of Behavional Sciences, 18, 63-73.

Hovey, J. D., \& King, C.A. (1996). Acculturative stress, depression, and suicidal ideation among immigrant and second-generation Latino adolescents, foumal of the American Academy of Child Adolexent Pychiatry, 35, 1183-1192.

Judy, R. W., \& D'Amico, C. D. (1999). Workforce 2020: Work and workers in the 21st century. Indianapolis, IN: Hudson Institute.

Kaplan, M. S., \& Marks, G. (1990). Adverse effects of acculturation: Psychological distress among Mexican American young adults. Social Science Medicine, 31, 1313-1319.

Livingston, A., \& Wirt, J. (2004). The condition of education 2004. U.S. Department of Education, National Center for Education Statistics. Washington, DC: U.S. Government Printing Office.

Ordonez-Jasis, R., \& Jasis, P. (2004). Rising with de colores: Tapping into the resources of la comunidad to assist under-performing Chicano-Latino students. Joumal of Latinos and Eitucation, 3, 53-64.

Pew Hispanic Center. (2004). Hispanic school achievement: Catching up requines numing faster than White youth. Washington, DC: Author.

Pew Hispanic Center. (2005). Hispanics: A people in motion. Washington, DC: Author.

Phinney, J. S., Cantu, C. L., \& Kurt/, D. A. (1997). Ethnic and American identity as predictors of selfesteem among African American, Latino, and White adolescents. Joumal of Youth and Adolescence, 26, 165-185.

Pina, A., Silverman, W., Fuentes, R., Kurtines, W., \& Weems, C. F. (2003). Exposure-based cognitivebehavioral treatment for phobic and anxiety disorders: Treatment effects and maintenance for Hispanic/Latino relative to European-American youths. Journal of the American Academy of Child and Adolescent Psychiatry, 42, 1179-1187.

Ponterotto, J. G. (1987). Counseling Mexican Americans: A multimodal approach. Journal of Counseling and Development, 65, 308-312.

Santiago-Rivera, A., Arredondo, P. M., \& Gallardo-Cooper, M. (2002). Counseling Latinos and la familia: A practical guide. Thousand Oaks, CA: Sage.

Schwarzbaum, S. E. (2004). Low-income Latinos and dropout: Strategies to prevent dropout. Joumal of Multicultural Counseling and Development, 32, 296-306.

Smart, J. F., \& Smart, D. W. (1995). Acculturative stress: The experience of the Hispanic immigrant. The Counseling Psychologist, 23, 25-42.

Szapocznik, J., Kurtines, W., \& Fernandez, T. (1980). Biculturalism and adjustment among Hispanic youths. Intemational Joumal of Interultural Relations, 4, 353-375.

Toro-Morn, M. I. (1998). The family and work experiences of Puerto Rican women migrants in Chicago. In H. McCubbin, E. Thompson, A. Thompson, \& J. Fromer (Eds.), Resiliency in Native American and immigrant families (pp. 277-294). Thousand Oaks, CA: Sage.

Torres-Rivera, E. (2004). Psychoeducational and counseling groups with Latinos. In J. DeLucia-Waack, D. Gerrity, C. Kalodner, \& M. Riva (Eds.), Handbook of group counseling and psychotherapy (pp. 213-223). Thousand Oaks, CA: Sage.

U.S. Census. (2003, June). The Hispanic population in the United States: March 2002 (United States Census No. P20-545). Washington, DC: Author.

U.S. Census. (2005a, June 9). Census Bureau neports: Hispanic population passes 40 million. Retrieved June 13 , 2005, from http://www.census.gov//Press-Release/www/releases/archives/population/005164.html

U.S. Census. (2005b, May). School enrollment-social and economic characteristics of students: October, 2003 (United States Census No. P20-554). Washington, DC: Author.

U.S. Department of Health and Human Services. (2001). Mental health: Culture, race, and ethnicity-A supplement to mental health: A report of the Surgeon General. Rockville, MD: Author.

Villalba, J. A. (2003). A psychoeducational group for limited-English proficient Latino/Latina Children. Journal for Specialists in Group Work, 28, 261-276.

Williams, C. L., \& Berry, J. W. (1991). Primary prevention of acculturative stress among refugees: Applications of psychological theory and practice. American Psychologist, 46, 632-641.

Zsembik, B. A., \& Fennell, D. (2005). Ethnic variation in health and the determinants of health among Latinos. Social Science and Medicine, 61, 53-63. 